\title{
OCULAR MANIFESTATIONS IN PATIENTS WITH ANAEMIA
}

\author{
V. Elisha Raju1 ${ }^{1}$ B. Malleswari ${ }^{2}$
}

${ }^{1}$ Assistant Professor, Department of Ophthalmology, Gandhi Medical College, Secunderabad, Telangana, India.

2Associate Professor, Department of Ophthalmology, GMC, Suryapet, Telangana, India.

\section{BACKGROUND}

ABSTRACT

Anaemia is a haematologic disorder presenting with ocular manifestations. It can affect all parts of the eye and adnexa, conjunctival pallor and retinopathy being common manifestations of nutritional anaemia. Retinal damage occurs due to hypoxia, venous stasis, angiospasm and increased capillary permeability. Incidence of retinopathy is increased with severity of anaemia.

The main aim of the study is to observe the involvement of different parts of the eye in anaemia and the eye manifestations in anaemia. The study included 120 patients diagnosed with anaemia due to various aetiologies.

\section{MATERIALS AND METHODS}

In this hospital-based cross-sectional study, 120 patients attending the medical outpatient in Gandhi Hospital, Secunderabad diagnosed with anaemia between July 2016-June 2018 were selected. All the patients were subjected to physical examination and complete blood picture. The patients with anaemia were identified and detailed ocular examination was done. Patients with positive fundus findings were subjected to fundus photographs with Topcon fundus camera. All the patients attending the medical outpatient department in Gandhi Hospital, Secunderabad, diagnosed with anaemia during the study period of 2 years from July 2016-June 2018 were included and thereby a sample size of 120 patients was considered as study population based on convenience sampling. Patients with Diabetes and Hypertension were excluded from the study.

\section{RESULTS}

Conjunctival pallor is the commonest finding observed in patients (93.3\%) out of 120 patients. Superficial retinal haemorrhages in $(34.1 \%)$ out of 120 patients. Deep retinal haemorrhages in (29.1\%). Posterior pole pallor in (46.6\%) patients out of 120 patients. Incidence of retinopathy is high in patients with severe anaemia and thrombocytopenia.

\section{CONCLUSION}

Anaemia can cause various ocular manifestations. Patients presenting with conjunctival pallor should be investigated for anaemia. Patients with moderate-to-severe anaemia should be subjected to fundus examination, as it may be associated with anaemic retinopathy. Severity of retinal haemorrhages depends on the severity of anaemia. Early diagnosis of anaemic retinopathy helps in early treatment of anaemia and thus resolution of retinal haemorrhages.

\section{KEY WORDS}

Anaemia, Retinopathy, Conjunctival Pallor, Fundus Examination.

HOW TO CITE THIS ARTICLE: Raju VE, Malleswari B. Ocular manifestations in patients with anaemia. J. Evolution Med. Dent. Sci. 2018;7(50):5333-5336, DOI: 10.14260/jemds/2018/1180

\section{BACKGROUND}

Anaemia is a haematological disorder presenting with various ocular manifestations. Conjunctival pallor and retinal haemorrhages are the predominant features.

Anaemia occurs when the RBC or haemoglobin are below the normal levels. The cause of anaemia may be due to defective production or abnormalities in the production of RBCs from the bone marrow (Erythropoiesis), increased blood loss or destruction of RBCs (Haemolysis).

Aplastic anaemia is due to bone marrow failure and occurs between 15 years and 25 years of age. It is due to immune-mediated destruction of the haematopoietic stem cells resulting in pancytopenia.

'Financial or Other Competing Interest': None.

Submission 16-11-2018, Peer Review 28-11-2018,

Acceptance 30-11-2018, Published 10-12-2018.

Corresponding Author:

Dr. B. Malleswari,

Flat No. 307, V. V. Vintage Residency,

Opp. IOB Bank, Rajbhavan Road,

Hyderabad-82,

Telangana, India.

E-mail: malleswari.bobbili@gmail.com

DOI: $10.14260 /$ jemds/2018/1180
Important factors related to aplastic anaemia include toxins, viral infections, drugs, autoimmune diseases and exposure to radiation. The clinical effects of anaemia depend on the duration and severity of anaemia. Aplastic anaemia can manifest as eyelid haematoma, subconjunctival haemorrhage, superficial haemorrhages, preretinal haemorrhages, vitreous haemorrhages, Roth spots, cotton wool spots and disc oedema. Haemorrhages can simulate central retinal vein obstruction. Some patients presented with papilloedema. Papilloedema in aplastic anaemia was thought to be due to raised intracranial pressure due to cerebral hypoxia.

Sickle cell anaemia can present with microvascular occlusion secondary to sickling of RBCs. Microvascular occlusion can lead to retinal hypoxia, ischaemia, infarction and neovascularisation. Sickle cell disease can manifest as central retinal artery occlusion, branch retinal occlusion, ischaemic optic neuropathy and chorioretinal infarction.

Anaemia can produce transient loss of vision due to retinal haemorrhages. Retinal haemorrhages were first described by Ulrich in 1983 associated with gastrointestinal haemorrhages.(1) 
The risk of retinopathy increases with the severity of anaemia, particularly when the haemoglobin falls below 6 gms\%.(2)

Anaemia causes retinal hypoxia, which leads to nerve fibre layer infarction and cotton wool exudates. Other pathological causes implicated are increased vascular permeability, venous stasis, angiospasm and increased blood viscosity.

The ocular manifestations of anaemia are dry eye, conjunctival haemorrhage, lid haematoma, orbital haemorrhage, retinal haemorrhage, subhyaloid haemorrhage, central retinal vein occlusion, vitreous haemorrhage, optic disc oedema and optic neuropathy.

Thrombocytopenia will be associated with anaemia in many situations causing coagulation defects and haemorrhages.

Loss of vision can be the presenting symptom in some of the cases due to haemorrhages or exudates in the macula or optic disc oedema or optic neuropathy.

\section{Retinal Changes in Anaemias are the following- Haemorrhages}

Dot and blot haemorrhages in the deep retinal layers. Superficial, flame-shaped haemorrhages in the nerve fibre layer are the most common finding in anaemic retinopathy. Subhyaloid haemorrhages may be present in some cases. Rarely, vitreous haemorrhage can occur.

\section{Cotton Wool Spots}

Retinal nerve fibre layer infarction can lead to white fluffy exudates.

\section{Hard Exudates}

These can be seen due to retinal oedema. When severe can produce macular star.

\section{Vessel Changes}

Arteriolar attenuation and dilated tortuous veins can be seen when severity of anaemia increases.

\section{Optic Nerve Changes}

Oedema, optic neuropathy and optic disc pallor in later stages.

In iron deficiency anaemia along with routine changes central retinal vein occlusion and artery occlusion, disc oedema and anterior ischaemic optic neuropathy can occur.(3) Vitamin B12 deficiency causes optic neuropathy.(4) Retinal pigment epithelial changes can occur in Thalassaemias.(5) Anaemia and raised intracranial pressure in Malaria can cause optic disc oedema.

In most of the cases, treatment of the underlying disease is sufficient. Retinopathy resolves without any treatment. Treatment is required if it is associated with vascular occlusions or macular oedema.

\section{MATERIALS AND METHODS}

This hospital-based cross-sectional study was conducted in 120 patients diagnosed with anaemia of various aetiologies attending medicine, gynaecology and surgery departments.
The study was done in the Department of Ophthalmology in Gandhi Hospital, Secunderabad during the period from July 2016-June 2018. Informed consent was taken from the patients. Complete haematological workup was done. Patients with diabetes and hypertension were excluded from the study. All the patients were examined for ocular manifestations in detail in Ophthalmology outpatient department.

All the patients attending the medical outpatient in Gandhi Hospital, Secunderabad diagnosed with anaemia, during the study period of 2 years from July 2016-June 2018 were included and thereby a sample size of 120 patients was considered as study population based on convenience sampling.

\begin{tabular}{|c|c|}
\hline Sex & Subjects \\
\hline Male & 45 \\
\hline Female & 75 \\
\hline \multicolumn{2}{|c|}{ Distribution of Sex } \\
\hline
\end{tabular}

Visual acuity of both eyes were done with Snellen's chart. Anterior segment of the eye was examined to detect lid oedema, conjunctival pallor and subconjunctival haemorrhage with torch light and slit lamp biomicroscope.

Posterior segment of the eye was thoroughly examined for retinal haemorrhages, cotton wool spots, macular star or optic disc oedema with the help of direct and indirect ophthalmoscope pictures were taken with Topcon fundus camera. The details of the patients with regard to the severity of anaemia, platelet counts, and ocular findings were recorded.

\begin{tabular}{|c|c|c|c|}
\hline Grading & Severe & Moderate & Mild \\
\hline Haemoglobin & $<6$ gms $\%$ & $6-<10$ gms $\%$ & $10-11$ gm $\%$ \\
\hline Total subjects & 32 & 50 & 28 \\
\hline Percentage $\%$ & $26.6 \%$ & $41.66 \%$ & $23.3 \%$ \\
\hline \multicolumn{3}{|c|}{ Distribution according to Severity of Anaemia } \\
\hline
\end{tabular}

Data was entered in Microsoft Excel and analysis was done using SPSS version 20. Descriptive statistical analysis was done. Results on categorical measurements were presented as percentages. Significance was assessed at 5\% level of significance. $\mathrm{P}<0.05$ was statistically significant. Fisher's exact test/ Chi-square test was used to find out the significance of study parameters on a categorical scale between two groups.

\begin{tabular}{|c|c|c|c|c|}
\hline $\begin{array}{c}\text { Grades of } \\
\text { Anaemia } \\
\text { (Hb in } \\
\text { gms\%) }\end{array}$ & $\begin{array}{c}\text { No. of Cases } \\
\text { of Anaemia } \\
\text { Studied }\end{array}$ & $\begin{array}{c}\text { No. of Cases } \\
\text { of Retinal } \\
\text { Haemorrhages }\end{array}$ & Ratio & $P$ value \\
\hline $\begin{array}{c}\text { Severe } \\
(<6 \text { gms } \%)\end{array}$ & 32 & $23(71.8 \%)$ & 3.5 & \\
\hline $\begin{array}{l}\text { Moderate - } \\
\text { Mild } \\
(6-11 \text { gms\%) }\end{array}$ & 78 & $16(20.5 \%)$ & 1 & $\mathrm{p}<0.05^{*}$ \\
\hline
\end{tabular}

Chi-square $\left(\mathrm{x}^{2}\right)=11.041, \mathrm{df}=1, \mathrm{p}<0.05 *$ (Statistically Significant). 


\begin{tabular}{|c|c|c|c|c|}
\hline $\begin{array}{c}\text { Platelet } \\
\text { Count x } 10^{9}\end{array}$ & $\begin{array}{c}\text { Haemoglobin } \\
\text { gm } \%\end{array}$ & $\begin{array}{l}\text { Total } \\
\text { Pts. }\end{array}$ & \begin{tabular}{c|c|} 
Retinal \\
Abnormalities
\end{tabular} & $\begin{array}{c}P \\
\text { value }\end{array}$ \\
\hline \multirow{3}{*}{$<50$} & $<6$ & 9 & $5(55.5 \%)$ & \multirow{9}{*}{$\begin{array}{c}\mathrm{p}< \\
0.05^{*}\end{array}$} \\
\hline & $6-<10$ & 12 & $5(41.6 \%)$ & \\
\hline & $! 0-11$ & 5 & $1(20 \%)$ & \\
\hline \multirow{3}{*}{$50-100$} & $<6$ & 13 & $4(30.7 \%)$ & \\
\hline & $6-<10$ & 16 & $2(12.5 \%)$ & \\
\hline & $! 0-11$ & 10 & 0 & \\
\hline \multirow[t]{3}{*}{$>100$} & $<6$ & 10 & $1(10 \%)$ & \\
\hline & $6-<10$ & 22 & 0 & \\
\hline & $10-11$ & 13 & 0 & \\
\hline \multicolumn{5}{|c|}{$\begin{array}{c}\text { Relation between Anaemia, Thrombocytopenia and } \\
\text { Retinal Abnormalities }\end{array}$} \\
\hline
\end{tabular}

Chi-square $\left(\mathrm{x}^{2}\right)=17.758, \mathrm{df}=8, \mathrm{p}<0.05 *$ (Statistically Significant).

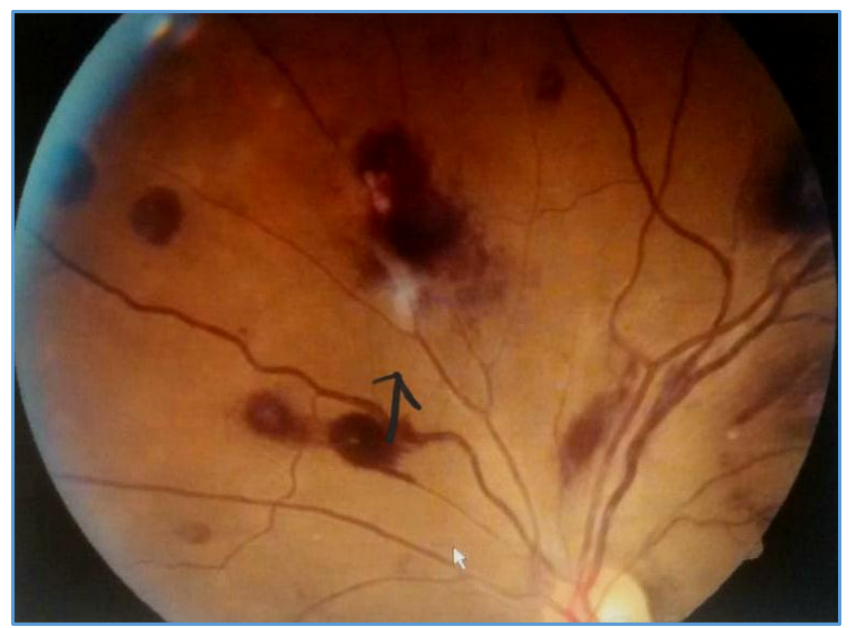

Figure 1. Pre-retinal Haemorrhages with Cotton Wool Spots in a patient with Severe Anaemia

\section{RESULTS}

In our study, conjunctival pallor was the commonest finding and was found in $93.3 \%$ of patients. Decreased vision was found in 35\% of patients. Lid oedema was found in 5\% of patients. Subconjunctival haemorrhages were found in $6.6 \%$ of patient. Retinal haemorrhage was the commonest finding in the fundus. Pallor of the fundus was the second commonest finding. Superficial and deep haemorrhages were found in $34.1 \%$ and $29.1 \%$, vitreous and subhyaloid haemorrhages in $13.3 \%$ of patients. Other findings like venous dilatation and tortuosity $15 \%$ of patients, macular oedema $5.8 \%$, papilloedema $8.3 \%$, macular oedema $5.8 \%$ and cotton wool spots $6.6 \%$ were found on fundus examination.

\begin{tabular}{|c|c|c|}
\hline Ocular Manifestations & Total Cases & Percentage \% \\
\hline Conjunctival pallor & 112 & $93.3 \%$ \\
\hline Diminished vision & 42 & $35 \%$ \\
\hline Lid oedema & 6 & $5 \%$ \\
\hline $\begin{array}{c}\text { Subconjunctival } \\
\text { haemorrhage }\end{array}$ & 8 & $6.66 \%$ \\
\hline Distribution of Ocular Manifestation in Anterior Segment \\
\hline
\end{tabular}

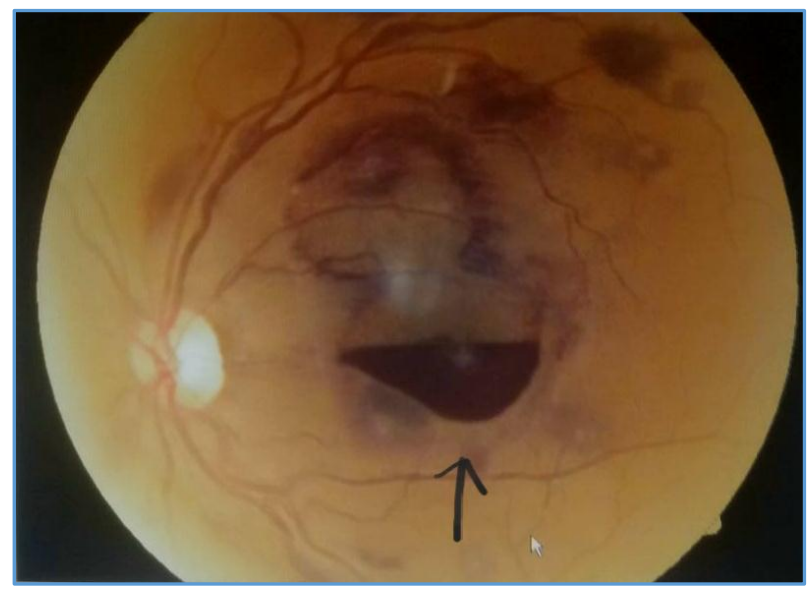

Figure 2. Subhyaloid Haemorrhage in Macular Area in patient with Severe Anaemia and Thrombocythemia

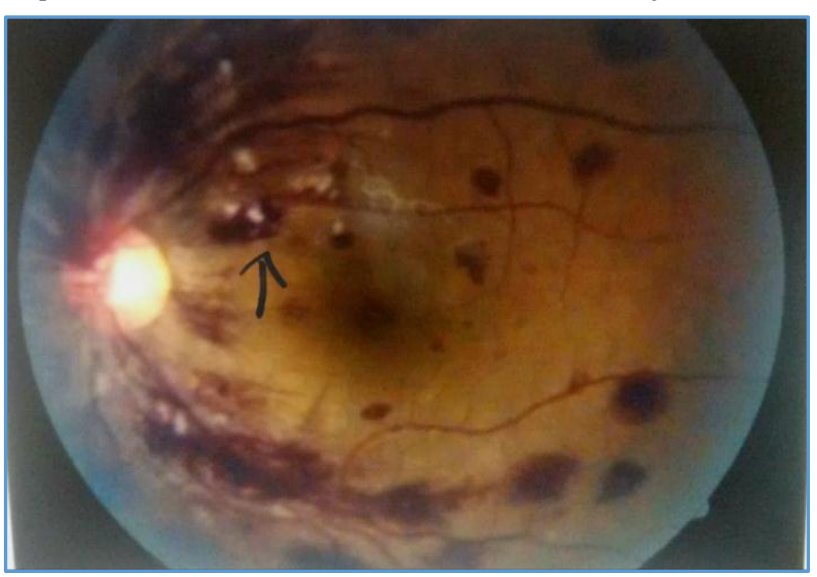

Figure 3. Flame-Shaped Haemorrhages with Cotton Wool Spots in Severe Anaemia

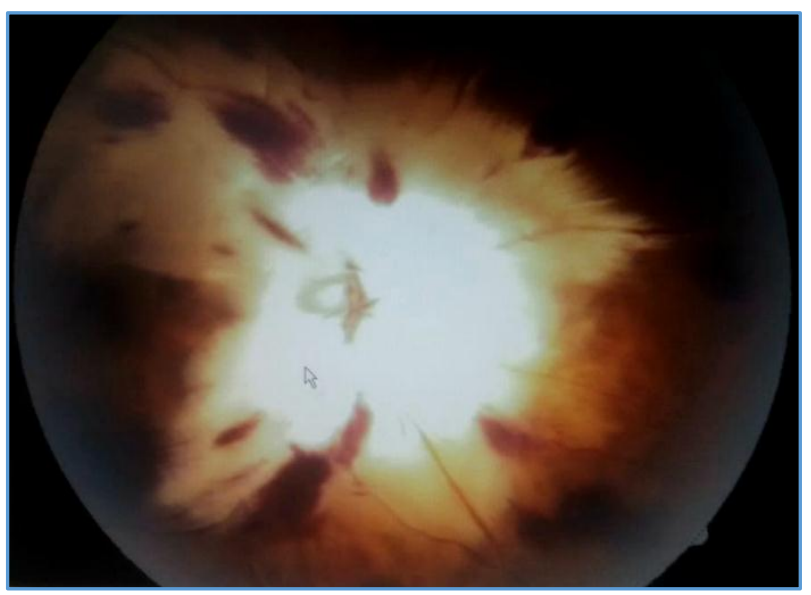

Figure 4. Papilloedema with Peripapillary Haemorrhages in Severe Anaemia with Thrombocythemia

\begin{tabular}{|c|c|c|}
\hline Retinal Findings & Total Cases & $\mathbf{\%}$ \\
\hline Fundal pallor & 56 & $46.6 \%$ \\
\hline Venous dilatation and tortuosity & 18 & $15 \%$ \\
\hline Papilloedema & 10 & $8.3 \%$ \\
\hline Vitreous/ Subhyaloid haemorrhage & 16 & $13.3 \%$ \\
\hline Cotton wool spots & 8 & $6.66 \%$ \\
\hline Macular star & 7 & $5.8 \%$ \\
\hline Flame-shaped haemorrhages & 41 & $34.1 \%$ \\
\hline Deep haemorrhages & 35 & $29.1 \%$ \\
\hline
\end{tabular}

Distribution of Ocular Manifestations in Posterior Segment 


\begin{tabular}{|c|c|c|c|c|}
\hline $\begin{array}{c}\text { Grades of } \\
\text { Anaemia } \\
\text { (Hb in gms\%) }\end{array}$ & $\begin{array}{c}\text { No. of Cases } \\
\text { of Anaemia } \\
\text { Studied }\end{array}$ & $\begin{array}{c}\text { No. of Cases of } \\
\text { Retinal } \\
\text { Haemorrhages }\end{array}$ & Ratio & P value \\
\hline $\begin{array}{c}\text { Severe } \\
(<6 \text { gms } \%)\end{array}$ & 32 & $23(71.8 \%)$ & 3.5 & $\mathrm{p}<0.05$ \\
\hline $\begin{array}{c}\text { Moderate-Mild } \\
(6-11 \text { gms } \%)\end{array}$ & 78 & $16(20.5 \%)$ & 1 & \\
\hline \multicolumn{4}{|c|}{ Association of Severity of Anaemia with Retinal } \\
Haemorrhages \\
\hline
\end{tabular}

In our study, the association between the haemoglobin level and retinal haemorrhages were also studied. In patients with mild-to-moderate anaemia presented with $20.5 \%$ of haemorrhages. Patients with severe anaemia presented with $71.8 \%$ of retinal haemorrhages. It was found that severity of retinopathy was more with severity of anaemia and found to be statistically significant. It was found in our study that retinal haemorrhages were increased in patients with concomitant severe anaemia and thrombocythemia. In patients with severe anaemia with platelet count $<50 \times 10^{9}$, the number of patients with retinal haemorrhages were statistically significant $(\mathrm{P}$ value $<0.05)$ as compared to patients with severe anaemia and platelet count $>100 \times 10^{9}$ ( $\mathrm{P}$ value). Rubenstein and Yanoff also showed that retinal abnormalities are increased in thrombocytopenia. (6)

Holt JM and Gordensmith studied 63 patients with anaemia and noted that flame-shaped haemorrhages were the commonest type of haemorrhages.(7)

\begin{tabular}{|c|c|c|c|}
\hline $\begin{array}{c}\text { Platelet } \\
\text { Count x 109 }\end{array}$ & $\begin{array}{c}\text { Haemoglobin } \\
\text { gm\% }\end{array}$ & Total Pts. & $\begin{array}{c}\text { Retinal } \\
\text { Abnormalities }\end{array}$ \\
\hline \multirow{3}{*}{$<50$} & $<6$ & 9 & $5(55.5 \%)$ \\
\cline { 2 - 4 } & $6-<10$ & 12 & $5(41.6 \%)$ \\
\cline { 2 - 4 } & $! 0-11$ & 5 & $1(20 \%)$ \\
\hline \multirow{3}{*}{$50-100$} & $<6$ & 13 & $4(30.7 \%)$ \\
\cline { 2 - 4 } & $6-<10$ & 16 & $2(12.5 \%)$ \\
\cline { 2 - 4 } & $! 0-11$ & 10 & 0 \\
\hline \multirow{3}{*}{$>100$} & $<6$ & 10 & $1(10 \%)$ \\
\cline { 2 - 4 } & $6-<10$ & 22 & 0 \\
\cline { 2 - 4 } & $! 0-11$ & 13 & 0 \\
\hline \multirow{3}{*}{ Relation between Anaemia, Thrombocytopenia and } \\
Retinal Abnormalities
\end{tabular}

$\mathrm{P}<0.05$.

\section{DISCUSSION}

Ocular manifestations of anaemias of various aetiologies can result in different ocular manifestations. Nutritional anaemia is the most common abnormality in India. It may be due to deficiency of iron, folic acid or Vit. B12. Iron deficiency is the commonest type of nutritional anaemia. Dr. Shitole Satish C, Dr. Jakkal Tapan $\mathrm{P}$ in their study reported maximum number of iron deficiency anaemia(8) among nutritional anaemias.

Lang GE et al reported that anaemic manifestations are uncommon in eye adnexa (like subconjunctival haemorrhage and lid oedema).(9) Merin S and Freund have found that in severe anaemia the retinal haemorrhages were found in $31.8 \%$ of patients, while in moderate anaemia it was found in $13.3 \%$ of patients.(10) In our study, retinal haemorrhages were present in $71.8 \%$ of patients with severe anaemia and $20.5 \%$ of patients with moderate anaemia.

\section{CONCLUSION}

The most common presentation was conjunctival pallor and haemorrhages, retinal haemorrhages and cotton wool spots. Retinopathy is a frequent finding in patients with severe anaemia. Retinopathy was found in all the patients with concomitant anaemia and thrombocytopenia. Ophthalmic manifestations do not require any specific treatment other than controlling thrombocytopenia and anaemia. Ocular symptoms can represent first sign of life-threatening systemic diseases like severe anaemia and thus facilitate timely diagnosis and treatment.

Thorough examination of the eye with a suspicion of systemic disease and control of the disease will help improve retinopathy associated with severe anaemia.(11)

\section{ACKNOWLEDGEMENTS}

I am very much thankful to the doctors for referring the patients to the Department of Ophthalmology. I am very much thankful to all the patients who were a vital part of the study.

\section{REFERENCES}

[1] Pears MA, Pickering GW. Changes in the fundus oculi after haemorrhage. Quart J Med 1960;29:153-78.

[2] Carraro MC, Rosetti L, Gerli GC. Prevalence of retinopathy in patients with anaemia or thrombocytopenia. Eur J Haematol 2001;67(4):23844.

[3] Imai E, Kunikata $\mathrm{H}$, Udono $\mathrm{T}$, et al. Branch retinal artery occlusion a complication of iron deficiency anaemia in a young adult with a rectal carcinoid. Tohoku J Exp Med 2004;203(2):141-4.

[4] Beck RW, Smith CH. Neurophthalmology: a problem oriented approach. Boston: Little, Brown and Co., 1988.

[5] Lowenstein JI. Retinopathy associated with blood anomalies. In: Jakobieck F, edr. Clinical Ophthalmology. Revised edn. Philadelphia: Lippincott 1995: p. 995-1000.

[6] Rubenstein RA, Yanoff M, Albert DM. Thrombocytopenia, anaemia and haemorrhage. Am J Ophthalmol 1968;65(3):435-9.

[7] Holt JM, Gordon-Smith EC. Retinal abnormalities in diseases of the blood. Brit J Ophthalmol 1969;53(3):145-60.

[8] Satish SC, Tapan JP. Ocular manifestations in patients with nutritional anaemia. Indian Journal of Basic and Applied Medical Research 2014;3(4):89-94.

[9] Lang GE, Spraul CW, Lang GK. Ocular changes in primary hematologic diseases. Klin Montsbl Augenheikd 1998;212(6):419-27.

[10] Merin S, Freund M. Retinopathy in severe anaemia. Am J Ophthalmol 1968;66(6):1102-6.

[11] Babu A, Bhatia K, Mathai A. Spontaneous bilateral peripapillary subhyaloid and vitreous hemorrhage in patients with severe anaemia secondary to ITP. Indian J Ophthalmol 2010;58(3):234-6. 